\title{
Penelitian Transfer Pricing di Indonesia: Sebuah Studi Kepustakaan
}

\author{
Amardianto Arham 1,*, Amrie Firmansyah ${ }^{2}$, Aji M. Elvin Nor ${ }^{3}$ \\ ${ }^{1}$ Jurusan Akuntansi; Politeknik Keuangan Negara STAN; Jl. Bintaro Utama Sektor V, \\ Bintaro, Tangerang Selatan; e-mail: arhamamardianto@gmail.com \\ ${ }^{2}$ Jurusan Akuntansi; Politeknik Keuangan Negara STAN; Jl. Bintaro Utama Sektor V, \\ Bintaro; e-mail: amrie.firmansyah@gmail.com \\ ${ }^{3}$ Jurusan Akuntansi; Politeknik Keuangan Negara STAN; Jl. Bintaro Utama Sektor V, \\ Bintaro, Tangerang Selatan; e-mail: ajimuhammadelvin@gmail.com \\ * Korespondensi: e-mail: arhamamardianto@ gmail.com
}

Diterima: 22 Maret 2020; Review: 20 April 2020; Disetujui: 21 April 2020

Cara sitasi: Arham A., Firmansyah A., \& Nor, A. M. E. 2020. Penelitian Transfer Pricing di Indonesia: Sebuah Studi Kepustakaan. Jurnal Online Insan Akuntan. Vol. 5 (1): 57-72.

\begin{abstract}
Abstrak: Penelitian ini bertujuan untuk melakukan pemetaan atas berbagai hasil penelitian terkait transfer pricing di Indonesia dan memberikan rekomendasi agenda riset transfer pricing di masa depan. Pemetaan dilakukan berdasarkan tingkat topik penelitian, metode penelitian, variabel penelitian, dan hasil pengujian. Penelitian ini menggunakan metode kualitatif dengan pendekatan bibliografi. Objek yang digunakan dalam penelitian ini yaitu sebanyak 41 artikel hasil penelitian yang diterbitkan oleh jurnal yang telah terakreditasi SINTA atau terindeks Scopus sejak tahun 2000 sampai dengan awal tahun 2020. Hasil penelitian menunjukkan bahwa mayoritas tingkat topik penelitian yang paling banyak dibahas yaitu determinan transfer pricing. Sebagian besar penelitian menggunakan metode kuantitatif. Mayoritas penelitian kuantitatif menggunakan transfer pricing aggressiveness sebagai variabel dependen. Sebagian besar penelitian kuantitatif menggunakan tiga variabel independen yaitu, pajak, tunneling incentive, dan mekanisme bonus. Mayoritas hasil pengujian atas pengaruh pajak dan tunneling incentive terhadap transfer pricing aggressiveness menunjukkan pengaruh positif, sedangkan mayoritas hasil pengujian atas pengaruh mekanisme bonus menunjukkan tidak ada pengaruh.
\end{abstract}

Kata kunci: Transfer Pricing, Penelitian, Indonesia.

\begin{abstract}
This study aims to map various research results related to transfer pricing in Indonesia and and provide recommendations on the transfer pricing research agenda in the future. Mapping is based on the research topics, research methods, research variables, and test results. This study uses a qualitative method with a bibliographic approach. The objects used in this study are 41 research articles published by SINTA accredited journals or Scopus indexed since 2000 until early 2020. The results show that the most discussed research topics are determinants in transfer pricing. The majority of quantitative studies use transfer pricing aggressiveness as dependent variable. Most quantitative studies use three independent variables namely, taxation, tunneling incentives, and bonus mechanisms. The majority of testing results on the effect of taxation and tunneling incentives on transfer pricing aggressiveness show a positive effect, while the majority of test results on the effect of the bonus mechanism show no effect.
\end{abstract} Keywords: Transfer Pricing, Research, Indonesia.

\section{Pendahuluan}

Dalam melaksanakan operasi bisnisnya, perusahaan tidak terlepas dari pembelian atau penjualan dengan pihak-pihak berelasi (Helena \& Firmansyah, 2018). 
Beberapa perusahaan memanfaatkan transaksi dengan pihak berelasi untuk melakukan transfer pricing. Namun, apabila transaksi tersebut dilakukan di berbagai wilayah yurisdiksi perpajakan dapat memberikan kesempatan yang cukup besar untuk melakukan penghindaran pajak (Desai et al., 2006). Pada dasarnya, transfer pricing merupakan penetapan harga barang dan jasa yang dipertukarkan antardivisi yang merupakan profit center dalam suatu perusahaan (Hirshleifer, 1956; Simamora, 1999; Hansen \& Mowen, 2005; Horngren et al., 2015). Selanjutnya, transfer pricing dikaitkan dengan adanya hubungan istimewa yang terjadi dalam transaksi internal suatu perusahaan dan antarperusahaan (Ikatan Akuntan Indonesia, 2013; Kurniawan, 2015; Santosa \& Suzan, 2018). Transfer pricing juga sering dikaitkan dengan aspek pajak terutama terkait penghindaran pajak (Feinschreiber, 2004; Suandy, 2011; Darussalam et al., 2013; Gusnardi, 2009).

Seiring dengan perkembangan globalisasi perdagangan, transfer pricing menjadi fokus perhatian perusahaan multinasional. Reese et al. (1989) mendefinisikan perusahaan multinasional sebagai perusahaan publik atau korporasi swasta yang memiliki setidaknya satu anak perusahaan asing atau divisi afiliasi. Studi yang dilakukan oleh World Trade Organization (2007) menunjukkan bahwa sekitar 70\% dari seluruh perdagangan global dihasilkan dari perusahaan multinasional. Hal yang serupa juga diungkapkan dalam penelitian Organization for Economic Cooperation and Development (OECD, 2017) yang mengungkapkan bahwa lebih dari $60 \%$ perdagangan global dilakukan oleh perusahaan multinasional yang berarti transfer pricing menjadi isu yang krusial.

Dalam ekspansi di pasar internasional, perusahaan multinasional memperoleh kesempatan yang tidak diperoleh di pasar domestik karena perbedaan dalam hal keunggulan kompetitif dengan negara-negara lain, seperti akses ke bahan mentah, akses ke pelanggan, biaya produksi, kemajuan teknologi, hingga kematangan infrastruktur (Ernst \& Young, 2011). Lin \& Chang (2010) juga menunjukkan bahwa perusahaan multinasional memperoleh berbagai manfaat dari perdagangan internasional, meliputi ekspansi dagang, kesempatan kerja, transfer teknologi, arus informasi pasar internasional, peningkatan promosi, penelitian dan pengembangan teknis, serta pertumbuhan ekonomi. 
Perusahaan multinasional mendorong terjadinya peningkatan integrasi ekonomi antarnegara (Hansen \& Rugraff, 2011). Dengan adanya kegiatan perdagangan yang dilakukan oleh perusahaan multinasional, jumlah transaksi perdagangan antarnegara meningkat baik dalam bentuk barang, jasa, aset tak berwujud, maupun aliran dana (Conover \& Nichols, 2000). Selain itu statistik menujukkan bahwa sebanyak 30\% transaksi internasional berasal dari perdagangan intragroup (United Nations, 2013).

Bernard et al. (2006) menyatakan bahwa transaksi intragroup bertentangan dengan prinsip kewajaran atau arm's length principles karena transaksi tersebut sengaja dibuat sedemikian rupa agar laba yang diperoleh digeser dan dilaporkan di negara yang bertarif pajak rendah (tax haven country) sedangkan biaya dialokasikan di negara yang bertarif pajak tinggi. Berdasarkan penelitian OECD (2006), ada sebanyak 39 negara yang termasuk tax haven country. Negara-negara tersebut memungkinkan adanya pergeseran pendapatan dari negara-negara bertarif pajak tinggi dan mengalihkan biaya secara berlawanan (Hamilton et al., 2001). Praktik inilah yang menyebabkan adanya transfer pricing aggressiveness yang berdampak pada penurunan jumlah pajak yang harus dibayarkan oleh perusahaan secara keseluruhan, termasuk di Indonesia (Sukanto, 2013).

Berdasarkan uraian permasalahan terkait transfer pricing di atas, perlu dilakukan pemetaan penelitian yang membahas mengenai transfer pricing agar dapat mengetahui sudah sejauh apa topik ini telah diulas dalam penelitian terdahulu. Pemetaan penelitian sudah banyak dilakukan dengan menggunakan pendekatan bibliografi. Pada konteks internasional, pendekatan bibliografi telah dieksplorasi dalam studi Hesford et al. (2007) yang melakukan pemetaan dalam bidang akuntansi manajemen dan Wang et al. (2019) yang memetakan penelitian terkait tax avoidance. Penelitian bibliografi juga telah dilakukan di Indonesia terkait penelitian pajak (Herawati \& Bandi, 2017; Arham et al., 2020b), penelitian manajemen pendapatan (Suprianto \& Setiawan, 2017), serta terkait adopsi IFRS (Aksan et al., 2019; Arham et al., 2020a; Wahyuni et al., 2020). Dalam berbagai penelitian bibliografi tersebut, pemetaan hasil penelitian dilakukan berdasarkan tahun penerbitan, jurnal penerbit, topik, metode, variabel, proksi, dan hasil pengujian serta memberikan rekomendasi agenda riset di masa depan mengenai topik penelitian yang dipetakan. 
Berdasarkan uraian di atas dan sejauh penelusuran literatur yang telah dilakukan, penelitian ini bertujuan untuk memetakan hasil penelitian terkait transfer pricing yang pertama di Indonesia. Pemetaan ini perlu dilakukan agar dapat menjadi panduan untuk riset-riset selanjutnya yang mengulas transfer pricing. Oleh karena itu, melalui penelitian ini dapat diketahui hasil penelitian sebelumnya yang mengulas topik transfer pricing di Indonesia mulai tahun 2000 sampai dengan awal tahun 2020 di bidang akuntansi. Berdasarkan pemetaan literatur yang telah dilakukan, penelitian ini menemukan 41 artikel hasil penelitian yang diterbitkan oleh jurnal yang telah terakreditasi nasional (SINTA) atau terindeks Scopus. Penelitian ini menguraikan metode penelitian yang digunakan, hasil dan pembahasan penelitian yang berisi pemetaan berdasarkan topik, metode, variabel, hasil pengujian, dan rekomendasi agenda penelitian transfer pricing di masa depan, serta diakhiri dengan simpulan, implikasi, dan keterbatasan penelitian.

\section{Metode Penelitian}

Penelitian ini menggunakan metode kualitatif dengan pendekatan bibliografi. Pendekatan bibliografi bertujuan untuk mengetahui perkembangan penelitian pada topik tertentu sehingga kesenjangan penelitian dapat ditemukan (Villas et al., 2008). Zoogah \& Rigg (2014) menyatakan bahwa ada tiga proses dalam melakukan penelitian bibliografi yaitu pengumpulan data, persiapan data, dan analisis data.

Pendekatan bibliografi dalam penelitian ini dilakukan melalui tiga tahap. Tahap pertama adalah pengumpulan data yang diawali dengan mencari berbagai artikel jurnal melalui laman Google Scholar dengan menggunakan kata kunci "transfer pricing di Indonesia". Artikel yang dikumpulkan hanyalah artikel dari jurnal yang telah terakreditasi SINTA atau terindeks Scopus dengan mengecek akreditasi jurnal melalui situs http://sinta.ristekbrin.go.id/journals (jurnal Indonesia) dan https://www.scimagojr.com/ (jurnal internasional). Tahap kedua adalah pengolahan data menggunakan aplikasi Microsoft Excel. Data-data dari artikel jurnal yang telah dikumpulkan berupa nama peneliti, tahun penerbitan, topik penelitian, metode penelitian, variabel penelitian, dan hasil pengujian dimasukkan ke dalam tabel yang menjadi database. Selanjutnya, dengan menggunakan fitur pivot table dalam aplikasi Microsoft Excel, tiap item data tersebut dianalisis untuk menemukan seberapa banyak 
item tersebut telah digunakan dalam penelitian untuk selanjutnya dipetakan dan disajikan dalam bentuk tabel. Tahap terakhir dalam pendekatan bibliografi pada penelitian ini adalah pengambilan kesimpulan berdasarkan hasil pemetaan. Kesimpulan berupa topik, metode, variabel, dan hasil pengujian yang paling banyak digunakan dan yang masih jarang digunakan sehingga dapat menjadi rekomendasi agenda riset transfer pricing di masa depan.

\section{Hasil dan Pembahasan}

Berdasarkan hasil penelitian bibliografi yang telah dilakukan, penelitian ini menemukan sebanyak 41 artikel jurnal yang membahas transfer pricing di Indonesia. Gambar 1 menunjukkan bahwa ulasan mengenai transfer pricing di Indonesia ternyata sudah mulai dilakukan oleh para peneliti sejak tahun 2000 dan paling banyak dipublikasikan pada tahun 2019.

\section{Gambar 1}

Pemetaan Berdasarkan Tahun Penerbitan

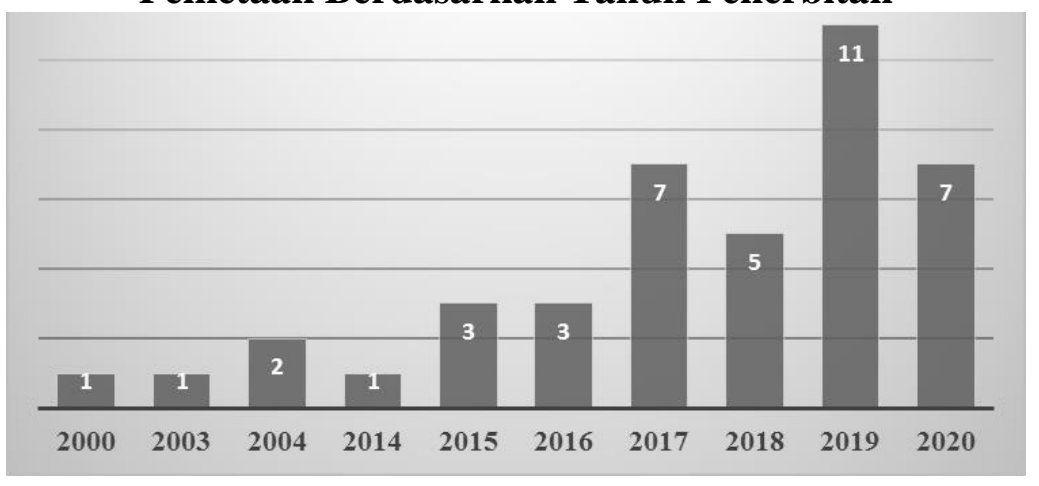

\subsection{Pemetaan Berdasarkan Topik Penelitian}

Langkah selanjutnya yang dilakukan dalam penelitian ini yaitu pemetaan berdasarkan topik penelitian. Dalam penelitian ini, yang dimaksud dengan topik penelitian adalah topik yang dibahas terkait hubungannya atau pengaruhnya dengan transfer pricing di Indonesia. Penelitian ini mengklasifikasikan topik penelitian secara eksplisit (dari judul penelitian) dan implisit (dengan melihat tujuan penelitian). 


\section{Tabel 1}

Pemetaan Berdasarkan Topik Penelitian

\begin{tabular}{lc}
\hline \multicolumn{1}{c}{ Topik } & Jumlah \\
\hline Determinan & 29 \\
Aspek Perpajakan & 6 \\
Lainnya & 6 \\
\hline \multicolumn{1}{c}{ Total } & $\mathbf{4 1}$
\end{tabular}

Tabel 1 menunjukkan bahwa mayoritas topik penelitian berkaitan dengan determinan atau faktor-faktor yang memengaruhi transfer pricing. Penjabaran informasi secara lebih lengkap mengenai daftar hasil penelitian yang memuat nama penulis, tahun penerbitan, serta topik penelitian dapat dilihat pada Lampiran 1.

\subsection{Pemetaan Berdasarkan Metode Penelitian}

Tabel 2

Pemetaan Berdasarkan Metode Penelitian

\begin{tabular}{cc}
\hline Metode & Jumlah \\
\hline Kuantitatif & 31 \\
Kualitatif & 10 \\
\hline \multicolumn{1}{c}{ Total } & $\mathbf{4 1}$
\end{tabular}

Sesuai Tabel 2, hasil penelitian terdahulu terkait transfer pricing di Indonesia lebih banyak menggunakan metode kuantitatif dibandingkan dengan metode kualitatif. Penggunaan metode kuantitatif dalam penelitian terkait transfer pricing di Indonesia bertujuan mengetahui pengaruh variabel-variabel lain terhadap transfer pricing atau sebaliknya dengan terlebih dahulu melakukan pengujian atas hipotesis. Sementara itu, metode kualitatif bertujuan menggali informasi dari berbagai sumber baik melalui telaah pustaka atau pendekatan lain sehubungan dengan topik transfer pricing di Indonesia.

\subsection{Pemetaan Berdasarkan Variabel Penelitian}

Penelitian ini melakukan pemetaan berdasarkan variabel penelitian yang digunakan dalam penelitian kuantitatif agar dapat mengetahui variabel-variabel apa saja yang digunakan dalam penelitian terdahulu dan menemukan variabel-variabel lain yang masih jarang diteliti. 
Tabel 3

Pemetaan Variabel Dependen

\begin{tabular}{lc}
\hline \multicolumn{1}{c}{ Variabel Dependen } & Jumlah \\
\hline Transfer Pricing Aggressiveness & 28 \\
Financial Reporting Aggressiveness & 1 \\
Pergeseran Laba dalam Transfer Pricing & 1 \\
Penghindaran Pajak & 1 \\
\hline \multicolumn{1}{c}{ Total } & $\mathbf{3 1}$
\end{tabular}

Tabel 3 menunjukkan bahwa variabel dependen yang paling banyak digunakan adalah variabel Transfer Pricing Aggressiveness. Sementara itu, Tabel 4 menunjukkan bahwa ada tiga variabel independen yang paling banyak digunakan dalam penelitian terkait transfer pricing di Indonesia yaitu, pajak, tunneling incentive, dan mekanisme bonus. Tabel 4 juga memberikan informasi bahwa variabel independen dalam penelitian transfer pricing di Indonesia sangat beragam yang dibuktikan dengan besarnya jumlah variabel independen Lainnya.

Tabel 4

\begin{tabular}{lc}
\multicolumn{2}{l}{ Pemetaan Variabel Independen } \\
\hline Variabel Independen & Jumlah \\
\hline Pajak & 21 \\
Tunneling Incentive & 18 \\
Mekanisme Bonus & 14 \\
Exchange Rate & 5 \\
Leverage & 4 \\
Ukuran Perusahaan & 4 \\
Intangible Assets & 3 \\
Kepemilikan Asing & 3 \\
Multinationality & 3 \\
Corporate Governance & 2 \\
Profitability & 2 \\
Transfer Pricing & 2 \\
Lainnya & 15
\end{tabular}

\subsection{Pemetaan Berdasarkan Hasil Pengujian}

Penelitian ini memetakan hasil pengujian yang menggunakan metode kuantitatif dengan berfokus pada tiga varibel independen yang paling banyak digunakan dalam penelitian transfer pricing aggressiveness di Indonesia, yaitu variabel Pajak, Tunneling Incentive, dan Mekanisme Bonus. Berdasarkan Tabel 5, mayoritas hasil pengujian atas pengaruh pajak terhadap transfer pricing aggressiveness menunjukkan adanya pengaruh positif. Adapun Tabel 6 menunjukkan bahwa mayoritas hasil pengujian atas pengaruh 
tunneling incentive terhadap transfer pricing aggressiveness menunjukkan adanya pengaruh positif. Sementara itu, Tabel 7 menunjukkan bahwa mayoritas hasil pengujian atas pengaruh mekanisme bonus terhadap transfer pricing aggressiveness menunjukkan tidak adanya pengaruh.

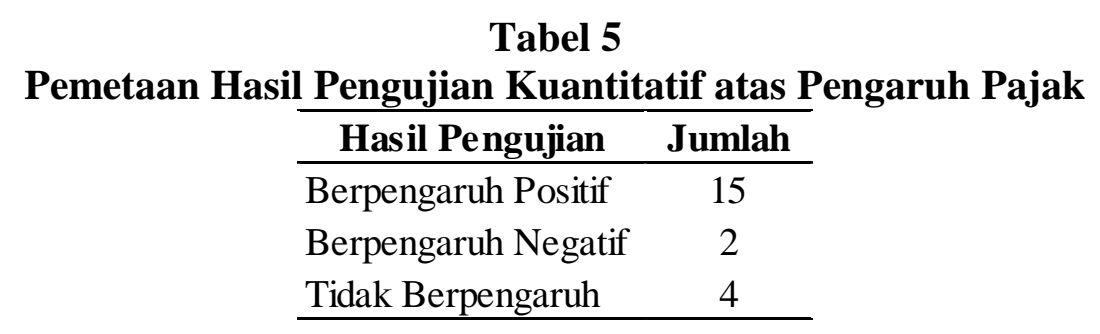

\section{Tabel 6}

Pemetaan Hasil Pengujian Kuantitatif atas Pengaruh Tunneling Incentive

\begin{tabular}{lc}
\hline \multicolumn{1}{c}{ Hasil Pengujian } & Jumlah \\
\hline Berpengaruh Positif & 13 \\
Berpengaruh Negatif & 1 \\
Tidak Berpengaruh & 4 \\
\hline
\end{tabular}

Tabel 7

Pemetaan Hasil Pengujian Kuantitatif atas Pengaruh Mekanisme Bonus

\begin{tabular}{lc}
\hline \multicolumn{1}{c}{ Hasil Pengujian } & Jumlah \\
\hline Berpengaruh Positif & 4 \\
Berpengaruh Negatif & - \\
Tidak Berpengaruh & 10 \\
\hline
\end{tabular}

\subsection{Agenda Riset Transfer Pricing di Masa Depan}

Berdasarkan pemetaan yang telah dilakukan, Tabel 7 menyajikan informasi tentang rekomendasi agenda riset transfer pricing berdasarkan topik penelitian, metode penelitian, variabel dependen, dan variabel independen. Penelitian ini mengkategorikan item-item tersebut sebagai rekomendasi agenda riset transfer pricing karena masih jarang atau baru satu kali diulas, belum pernah diulas, atau hasil pengujiannya masih menunjukkan inkonsistensi. 
Tabel 7

Agenda Riset Transfer Pricing di Masa Depan

\begin{tabular}{ll}
\hline \multicolumn{1}{c}{ Item } & \multicolumn{1}{c}{ Rekomendasi } \\
\hline \multirow{2}{*}{ Topik } & $\begin{array}{l}\text { Aspek Perpajakan, Pengaruh terhadap Financial Reporting Aggressiveness, Skema, } \\
\text { Pengaruh terhadap Kepatuhan Pembebanan Biaya Promosi, Persepsi Pemeriksa Pajak, } \\
\text { atau Determinan }\end{array}$ \\
\hline Metode & Kuantitatif atau Kualitatif \\
\hline Variabel Dependen & $\begin{array}{l}\text { Transfer Pricing Aggressiveness, Financial Reporting Aggressiveness, Pergeseran Laba } \\
\text { dalam Transfer Pricing, atau Penghindaran Pajak }\end{array}$ \\
\hline \multirow{2}{*}{ Variabel Independen } & $\begin{array}{l}\text { Financial Derivatives, Financial Leverage, Agency Cost, Company Operation } \\
\text { Complexity, Debt Covenant, Foreign Sales, KAP Spesialisasi, Persentase Komisaris } \\
\text { Independen, R\&D Expenditure, Sales Growth, Tax Haven Utilization, Corporate } \\
\text { Moral Ethics, atau FDI Enterprise Earnings }\end{array}$ \\
\hline
\end{tabular}

\section{Kesimpulan}

Penelitian ini bertujuan untuk melakukan pemetaan atas berbagai hasil penelitian terkait transfer pricing di Indonesia. Pemetaan dilakukan berdasarkan topik penelitian, metode penelitian, variabel penelitian, dan hasil pengujian. Penelitian ini menggunakan metode kualitatif dengan pendekatan bibliografi. Objek yang digunakan dalam penelitian ini yaitu sebanyak 41 artikel hasil penelitian yang diterbitkan oleh jurnal yang telah terakreditasi SINTA atau terindeks Scopus sejak tahun 2000 sampai dengan awal tahun 2020.

Hasil penelitian menunjukkan bahwa topik penelitian yang paling banyak dibahas yaitu determinan transfer pricing. Sebagian besar penelitian menggunakan metode kuantitatif dengan transfer pricing aggressiveness sebagai variabel dependen dan sebagian besar menggunakan tiga variabel independen yaitu, pajak, tunneling incentive, dan mekanisme bonus. Mayoritas hasil pengujian atas pengaruh pajak dan tunneling incentive terhadap transfer pricing aggressiveness menunjukkan pengaruh positif, sedangkan mayoritas hasil pengujian atas pengaruh mekanisme bonus menunjukkan tidak ada pengaruh. Penelitian selanjutnya sebaiknya tidak lagi menguji pengaruh pajak, tunneling incentive, dan mekanisme bonus terhadap transfer pricing aggressiveness karena mayoritas sudah menunjukkan hasil yang sama.

Penelitian ini diharapkan dapat memberikan kontribusi berupa research gap yang bisa dijadikan bahan penelitian selanjutnya bagi para akademisi. Penelitian ini hanya melakukan pemetaan berdasarkan topik, metode, variabel, dan hasil pengujian. Penelitian selanjutnya yang menggunakan pendekatan studi kepustakaan dapat melengkapi penelitian ini berdasarkan teori penelitian, unit analisis, jumlah cakupan 
tahun analisis, jumlah sampel, proksi, serta penerbit dan tingkat akreditasinya. Penelitian selanjutnya juga dapat melakukan analisis menggunakan pendekatan data mining untuk menggali lebih dalam terkait pola-pola tertentu dalam penelitian mengenai transfer pricing di Indonesia karena pendekatan data mining dapat mengekstraksi dan mengidentifikasi informasi yang bermanfaat dan pengetahuan yang terkait dari berbagai database yang besar. 


\section{Referensi}

Aksan, I., Setiawan, D., \& Gantyowati, E. (2019). Research Development Related to Implementation of Financial Accounting Standards in Indonesia. International Journal of Economics, Business and Accounting Research (IJEBAR), 3(04), 420434.

Anggraeni, N., \& Lutfillah, N. Q. (2019). Determinants of Transfer Pricing. Journal of Management and Business, 18(2), 46-55.

Arham, A., Firmansyah, A., Nor, A. M. E., \& Vito, B. (2020a). A Bibliographic Study on IFRS Adoption Research in Indonesia. International Journal of Psychosocial Rehabilitation, 24(7), 9477-9501.

Arham, A., Firmansyah, A., Nor, A. M. E., \& Vito, B. (2020b). A Bibliographic Study on Tax Avoidance Research in Indonesia. International Journal of Psychosocial Rehabilitation, 24(7), 9526-9554.

Azzura, C. S., \& Pratama, A. (2019). Influence of Taxes, Exchange Rate, Profitability, and Tunneling Incentive on Company Decisions of Transferring Pricing. JABI (Jurnal Akuntansi Berkelanjutan Indonesia), 2(1), 123-133.

Bernard, A. B., Jensen, J. B., \& Schott, P. K. (2006). Transfer pricing by US-based multinational firms (No. w12493). National Bureau of Economic Research.

Conover, T. L., \& Nichols, N. B. (2000). A further examination of income shifting through transfer pricing considering firm size and/or distress. The International Journal of Accounting, 35(2), 189-211.

Darussalam, D. S., \& Kristiaji, B. B. (2013). Transfer Pricing Ide, Strategi, dan Panduan Praktis dalam Perspektif Pajak Internasional. Jakarta: Danny Darussalam Tax Center.

Desai, M. A., Foley, C. F., \& Hines Jr, J. R. (2006). The demand for tax haven operations. Journal of Public economics, 90(3), 513-531.

Dinca, M. H., \& Fitriana, V. E. (2019). Do R\&D Expenditure, Multinationality and Corporate Governance Influence Transfer Pricing Aggressiveness? Jurnal Akuntansi dan Bisnis: Jurnal Program studi Akuntansi, 5(2), 102-114.

Djuhartika, H. (2003). Kajian Pasal 18 Ayat (3) Hurufa Uu Pph Tahun 2000: Advance Pricing Agreement Sebagai solusi Praktek Transfer Pricing di Indonesia. Mimbar Hukum, 10.

Ernst \& Young. (2011). Tracking Global Trend: How Six Key Developments are shaping the Business World?

Feinschreiber, R. (2004). Transfer pricing methods: An applications guide. John Wiley \& Sons.

Firmansyah, A., \& Yunidar, A. (2020). Financial Derivatives, Financial Leverage, Intangible Assets, and Transfer Pricing Aggressiveness: Evidence from Indonesian Companies. Jurnal Dinamika Akuntansi dan Bisnis, 7(1), 1-14.

Gusnardi, G. (2009). Penetapan Harga Transfer dalam Kajian Perpajakan. Jurnal Pendidikan Ekonomi dan Bisnis, 1(01), 8926.

Hamilton, R., Deutsch, R. L., \& Raneri, J. (2001). Guidebook to Australian international taxation. LexisNexis Butterworths.

Hansen, D. R., \& Mowen, M. M. (2005). Managerial Accounting Edisi ke-8. Mason: Thomson Higher Education.

Hansen, M. W., \& Rugraff, E. (2011). Multinational corporations and local firms in emerging economies (p. 276). Amsterdam University Press. 
Helena, R., \& Firmansyah, A. (2018). Pengungkapan Pihak-Pihak Berelasi pada Perusahaan-Perusahaan Salim Group yang Terdaftar di Bursa Efek Indonesia. Jurnal Online Insan Akuntan, 3(2), 185-196.

Herawati, N., \& Bandi, B. (2017). Dua puluh tahun riset perpajakan dalam akuntansi: Suatu studi bibliografi. Jurnal Akuntansi dan Keuangan, 19(2), 102-121.

Herawaty, V., \& Anne, A. (2019). Pengaruh Tarif Pajak Penghasilan, Mekanisme Bonus, dan Tunneling Incentives terhadap Pergeseran Laba Dalam Melakukan Transfer Pricing dengan Good Corporate Governance sebagai Variabel Moderasi. Jurnal Akuntansi Trisakti, 4(2), 141-156.

Herianti, E., \& Marundha, A. (2019). Transfer Pricing, Agency Costs, and Financial Reporting Aggressiveness: An Empirical Study in Indonesia. Journal of Accounting and Investment, 20(3), 325-338.

Hesford, J. W., Lee, S. H. S., Van der Stede, W. A., \& Young, S. M. (2006). Management accounting: a bibliographic study. Handbooks of management accounting research, 1, 3-26.

Hirshleifer, J. (1956). On the economics of transfer pricing. The Journal of Business, 29(3), 172-184.

Ikatan Akuntan Indonesia. (2013). Model Pelatihan Pajak Brevet C Cetakan ke-6. Jakarta: Ikatan Akuntansi Indonesia.

Indriaswari, Y. N., \& Nita, R. A. (2018). The influence of tax, tunneling incentive, and bonus mechanisms on transfer pricing decision in manufacturing companies. The Indonesian Accounting Review, 7(1), 69-78.

Jumaidi, L. T., Bambang, B., \& Hudaya, R. (2017). Analisis Pajak, Tunneling, Gross Margin, dan Kap Spesialis terhadap Keputusan untuk Melakukan Transfer Pricing. Jurnal Aplikasi Akuntansi, 1(2), 1-1.

Kesa, D. D., Harinurdin, E., \& Setiawati, A. (2016). ANALISIS TRANFER PRICING DALAM LENDING ACTIVITIES BANKING DENGAN MENGGUNAKAN ARM'S LENGTH PRINCIPLE. Jurnal Vokasi Indonesia, 3(2).

Kurniawan, A. M. (2015). Pajak Internasional Edisi Kedua (International Tax Second Edition). Jakarta: Ghalia Indonesia.

Liana, S., Poulus, S., \& Pratama, A. (2020). The Effect of Share Ownership Concentration and Company Operation Complexity towards Transfer Pricing Decisions. Journal of Accounting Auditing and Business, 3(1), 52-61.

Lin, C. W., \& Chang, H. C. (2010). Motives of transfer pricing strategies-systemic analysis. Industrial Management \& Data Systems, 110(8), 1215-1233.

Mangoting, Y. (2000). Aspek perpajakan dalam praktek transfer pricing. Jurnal Akuntansi dan Keuangan, 2(1), 69-82.

Marfuah, M., \& Azizah, A. P. N. (2014). Pengaruh pajak, tunneling incentive dan exchange rate pada keputusan transfer pricing perusahaan. Jurnal Akuntansi dan Auditing Indonesia, 18(2), 156-165.

Mispiyanti, M. (2015). Pengaruh Pajak, Tunneling Incentive dan Mekanisme Bonus Terhadap Keputusan Transfer Pricing. Journal of Accounting and Investment, 16(1), 62-74.

Muhammadi, A. H., Ahmed, Z., \& Habib, A. (2016). Multinational transfer pricing of intangible assets: Indonesian tax auditors' perspectives. Asian Review of Accounting, 24(3), 313-337. 
Mulyani, H. S., Prihartini, E., \& Sudirno, D. (2020). Analisis Keputusan Transfer Pricing Berdasarkan Pajak, Tunneling dan Exchange Rate. Jurnal Akuntansi dan Pajak, 20(2), 171-181.

Novira, A. R., Suzan, L., \& Asalam, A. G. (2020). Pengaruh Pajak, Intangible Assets, dan Mekanisme Bonus Terhadap Keputusan Transfer Pricing. Journal of Applied Accounting and Taxation, 5(1), 17-23.

OECD, Đ. S. (2006). The OECD's Project on Harmful Tax Practices: 2006 Update on Progress in Member Countries.

OECD. (2017). Transfer Pricing for Multinational Enterprise and Tax Administrations Guidelines.

Panjalusman, P. A., Nugraha, E., \& Setiawan, A. (2018). Pengaruh Transfer Pricing Terhadap Penghindaran Pajak. JPAK: Jurnal Pendidikan Akuntansi dan Keuangan, 6(2), 105-114.

Permatasari, P. (2004). Transfer Pricing Sebagai Salah Satu Strategi Perencanaan Pajak Bagi Perusahaan Multi Nasional. Bina Ekonomi, 8(1), 47-63.

Pratama, A. (2020). Corporate governance, foreign operations and transfer pricing practice: the case of Indonesian manufacturing companies. International Journal of Business and Globalisation, 24(2), 185-200.

Putri, V. R. (2019). Analisis Faktor yang Mempengaruhi Transfer Pricing pada Perusahaan Manufaktur di Indonesia. Jurnal Manajemen Dayasaing, 21(1), 1-11.

Putri, W. A. (2017). Prinsip kewajaran dan dokumen sebagai penangkal kecurangan transfer pricing di Indonesia. Jurnal Penelitian Teori \& Terapan Akuntansi (PETA), 2(2), 87-97.

Rachmat, R. A. H. (2019). Pajak, Mekanisme Bonus dan Transfer Pricing. JPAK: Jurnal Pendidikan Akuntansi dan Keuangan, 7(1), 21-30.

Rahayu, T. T., Wahyuningsih, E. M., \& Wijayanti, A. (2020). Pengaruh Beban Pajak, Exchange Rate, Tunneling Incentive, Profitabilitas dan Leverage Terhadap Keputusan Transfer Pricing. Jurnal Penelitian Ekonomi dan Akuntansi, 5(1), 7890.

Reese, R. A., Henneberry, S. R., \& Russell, J. R. (1989). Transfer pricing in multinational firms: A review of the literature. Agribusiness, 5(2), 121-137.

Rezky, M. A., \& Fachrizal, F. (2018). Pengaruh Mekanisme Bonus, Ukuran Perusahaan, Leverage, dan Multinationality terhadap Keputusan Transfer Pricing pada Perusahaan Manufaktur yang Terdaftar di Bursa Efek Indonesia Tahun 20102014. Jurnal Ilmiah Mahasiswa Ekonomi Akuntansi, 3(3), 401-415.

Saifudin, S., \& Putri, S. (2018). Determinasi Pajak, Mekanisme Bonus, dan Tunneling Incentive terhadap Keputusan Transfer Pricing pada Emiten BEI. Agregat: Jurnal Ekonomi dan Bisnis, 2(1), 32-43.

Santosa, S. J. D., \& Suzan, L. (2018). Pengaruh Pajak, Tunneling Incentive dan Mekansme Bonus Terhadap Keputusan Transfer Pricing (Studi Kasus pada Perusahaan Sektor Industri Barang Konsumsi yang Terdaftar di Bursa Efek Indonesia Tahun 2013-2016). Kajian Akuntansi, 19(1), 72-80.

Santoso, I. (2004). Advance pricing Agreement dan problematika transfer pricing dari perspektif perpajakan Indonesia. Jurnal akuntansi dan keuangan, 6(2), 123-139.

Saraswati, R. S., \& Sujana, I. K. (2017). Pengaruh Pajak, Mekanisme Bonus, dan Tunneling Incentive Pada Indikasi Melakukan Transfer Pricing. E-Jurnal Akuntansi, 1000-1029. 
Sarifah, D. A., Probowulan, D., \& Maharani, A. (2019). Dampak Effective Tax Rate (ETR), Tunneling Incentive (TNC), Indeks Trend Laba Bersih (ITRENDLB) Dan Exchange Rate Pada Keputusan Transfer Pricing Perusahaan Manufaktur Yang Listing Di Bursa Efek Indonesia (BEI). Jurnal Ilmiah Akuntansi dan Humanika, 9(2).

Sentanu, A. I., \& Juliani, B. I. H. (2016). Analisis Yuridis Terhadap Transfer Pricing Sebagai Upaya Tax Avoidance (Penghindaran Pajak). Diponegoro Law Journal, 5(2), 1-15.

Shodiq, J., Widjajanti, K., \& Rusdianti, E. (2017). Determinan Keputusan Transfer Pricing (Studi pada Perusahaan Manufaktur yang Terdaftar di Bei Tahun 20112014). Jurnal Riset Ekonomi dan Bisnis, 10(2), 85-105.

Simamora, H. (1999). Akuntansi Manajemen. Jakarta: Salemba Empat.

Suandy, E. (2011). Perencanaan Pajak Edisi Kelima. Jakarta: Salemba Empat.

Sukanto, T. (2013). Tax Avoidance through Tax Havens and Transfer Pricing - A Case Study in Indonesia. American Journal of Business, Economics, and Management, $1(1), 25-29$.

Sulistyawati, A. I., Santoso, A., \& Rokhawati, L. (2020). Determinant detection of transfer pricing decisions. Accountability, 9(1), 16-27.

Suparno, \& Suwarjuwono, T. (2019). Skema Transfer Pricing pada Perusahaan Pertambangan dan Faktor-Faktor yang Terlibat. E-Jurnal Akuntansi, 29(2), 765778.

Suprianto, E., \& Setiawan, D. (2017). Manajemen Laba di Indonesia: Sebuah Studi Bibliografi. Jurnal Keuangan dan Perbankan, 21(040), 287-301.

Supriyadi. (2019). Perilaku Perusahaan Multinasional dan Aggressive Transfer Pricing Practices terhadap Kepatuhan Pembebanan Biaya Promosi (Studi Kasus pada PT MSM). Majalah Ilmiah Bijak, 16(2), 85-92.

Susanti A., \& Firmansyah, A. (2018). Determinants of Transfer Pricing Decisions in Indonesia Manufacturing Companies. Jurnal Akuntansi dan Auditing Indonesia, 22(2), 81-93.

Tiwa, E. M., Saerang, D. P., \& Tirayoh, V. (2017). Pengaruh Pajak dan Kepemilikan Asing Terhadap Penerapan Transfer Pricing pada Perusahaan Manufaktur yang Terdaftar di BEI tahun 2013-2015. Jurnal EMBA: Jurnal Riset Ekonomi, Manajemen, Bisnis dan Akuntansi, 5(2), 2666-2675.

United Nations. (2013). United Nations Practical Manual on Transfer Pricing for Developing Countries. New York: United Nations.

Villas, M. V., Macedo-Soares, T. D. L., \& Russo, G. M. (2008). Bibliographical research method for business administration studies: a model based on scientific journal ranking. BAR-Brazilian Administration Review, 5(2), 139-159.

Wafiroh, N. L., \& Hapsari, N. N. (2015). Pajak, Tunneling Incentive Dan Mekanisme Bonus Pada Keputusan Transfer Pricing. EL MUHASABA: Jurnal Akuntansi (eJournal), 6(2), 157-168.

Wahyuni, E. T., Puspitasari, G., \& Puspitasari, E. (2020). Has IFRS improved Accounting Quality in Indonesia? A Systematic Literature Review of 20102016. Journal of Accounting and Investment, 1(1), 19-44.

Wang, F., Xu, S., Sun, J., \& Cullinan, C. P. (2019). Corporate Tax Avoidance: A Literature Review and Research Agenda. Journal of Economic Surveys, 1-19. 
Waworuntu, S. R., \& Hadisaputra, R. (2016). Determinants of Transfer Pricing Aggressiveness in Indonesia. Pertanika Journal of Social Science and Humanities, 24(5), 95-110.

World Trade Organization. (2007). Trade Liberalisation Statistics.

Yulia, A., Hayati, N., \& Daud, R. M. (2019). The Influence of Tax, Foreign Ownership and Company Size on the Application of Transfer Pricing in Manufacturing Companies Listed on IDX during 2013-2017. International Journal of Economics and Financial Issues, 9(3), 175.

Yulianti, S., \& Rachmawati, S. (2019). Tax Minimization Sebagai Pemoderasi Pada Pengaruh Tunnelling Incentive Dan Debt Convenant Terhadap Ketetapan Transfer Pricing. Jurnal Akuntansi Berkelanjutan Indonesia, 2(2).

Zoogah, D. B., \& Rigg, J. S. (2014). Bibliographic Analysis and Strategic Management Research in Africa', Advancing Research Methodology in the African Context: Techniques, Methods, and Designs. Research Methodology in Strategy and Management, 10, 189-213. 


\section{LAMPIRAN 1}

\begin{tabular}{|c|c|c|c|}
\hline No & Nama Penulis & Tahun & Topik \\
\hline 1 & Anggraeni \& Lutfillah & 2019 & Determinan \\
\hline 2 & Azzura \& Pratama & 2019 & Determinan \\
\hline 3 & Dinca \& Fitriana & 2019 & Determinan \\
\hline 4 & Djuhartika & 2003 & Aspek Perpajakan \\
\hline 5 & Firmansyah \& Yunidar & 2020 & Determinan \\
\hline 6 & Herawaty \& Anne & 2017 & Determinan \\
\hline 7 & Herianti \& Marundha & 2019 & Pengaruh terhadap Financial Reporting Aggressiveness \\
\hline 8 & Indriaswari \& Aprillia & 2017 & Determinan \\
\hline 9 & Jumaidi et al. & 2017 & Determinan \\
\hline 10 & Kesa et al. & 2015 & Skema \\
\hline 11 & Liana et al. & 2020 & Determinan \\
\hline 12 & Mangoting & 2000 & Aspek Perpajakan \\
\hline & Marfuah \& Azizah & 2014 & Determinan \\
\hline 14 & Mispiyanti & · 2015 & Determinan \\
\hline 15 & Muhammadi et al. & 2016 & Persepsi Pemeriksa Pajak \\
\hline & Mulyani et al. & 2020 & Determinan \\
\hline 17 & Novira et al. & 2020 & Determinan \\
\hline 18 & Panjalusman et al. & 2018 & Pengaruh terhadap Penghindaran Pajak \\
\hline 19 & Permatasari & 2004 & Aspek Perpajakan \\
\hline 20 & Pratama & 2020 & Determinan \\
\hline & Putri & 2017 & Aspek Perpajakan \\
\hline & Putri & 2019 & Determinan \\
\hline 23 & Rachmat & 2019 & Determinan \\
\hline 24 & Rahayu et al. & 2020 & Determinan \\
\hline & Rezky \& Fachrizal & 2018 & Determinan \\
\hline 26 & Saifudin \& Putri & 2018 & Determinan \\
\hline & Santosa \& Suzan & 2018 & Determinan \\
\hline & Santoso & 2004 & Aspek Perpajakan \\
\hline & Saraswati \& Sujana & 2017 & Determinan \\
\hline & Sarifah et al. & 2019 & Determinan \\
\hline & Sentanu et al. & 2016 & Aspek Perpajakan \\
\hline & Shodiq et al. & 2017 & Determinan \\
\hline 33 & Sulistyawati et al. & 2020 & Determinan \\
\hline & Suparno \& Suwarjuwono & 2019 & Skema \& Determinan \\
\hline & Supriyadi & 2019 & Pengaruh terhadap Kepatuhan Pembebanan Biaya Promosi \\
\hline & Susanti \& Firmansyah & 2018 & Determinan \\
\hline & Tiwa et al. & 2017 & Determinan \\
\hline & Wafiroh \& Hapsari & 2015 & Determinan \\
\hline & Waworuntu \& Hadisaputra & 2016 & Determinan \\
\hline & Yulia et al. & 2019 & Determinan \\
\hline & Yulianti \& Rachmawati & 2019 & Determinan \\
\hline
\end{tabular}

